\title{
EL ABRIGO TLALOC: ANÁLISIS E INTERPRETACIÓN DE UN CONJUNTO RUPESTRE DESTINADO AL DIOS DE LA LLUVIA Y LA AGRICULTURA (TICUMÁN, MÉXICO)
}

\author{
Abrigo Tlaloc: Analysis and interpretation of a rock art panel \\ dedicated to the god of rain and agriculture (Ticumán , Mexico)
}

\author{
Roberto Martínez, Luis Morett y Ramón Viñas* \\ Recibido el 12 de diciembre de 2007. Aceptado el 20 de enero de 2008.
}

Resumen. El presente trabajo sintetiza los estudios publicados sobre este conjunto rupestre mexicano, divulgado como Abrigo Tlaloc por la presencia de diversas representaciones pictóricas del dios mesoamericano de la tierra, la lluvia y la agricultura. Por una parte, se presentan las interpretaciones del mural, donde se conjuga el análisis de sus frisos con el contexto arqueológico, y la información etnohistórica y etnográfica y, por otra, se exponen las intervenciones arqueológicas efectuadas en este espacio rupestre y cuevas circundantes.

Palabras clave: Arte rupestre. Etnografía. Mitología. Mesoamérica. Tlaloc. México precolombino.

Abstract. This paper synthesizes various publications on a Mexican rock art site known as Abrigo Tlaloc due to the presence of several pictorial representations of this Mesoamerican god of the earth, rain and agriculture. In first instance, interpretations of the mural are given, which combine an analysis of the panel in an archaeological context with ethnohistorical and ethnographical data. Secondly, a summary of archaeological works carried out in this rock shelter and surrounding caves is made.

Key Words: Rock Art. Ethnography. Mythology. Mesoamerica. Tlaloc. Precolumbian Mexico.

\section{ANTECEDENTES}

Al iniciar la década de los años noventa (siglo XX), y como resultado de las prácticas de un curso de Arte Rupestre, impartido en la Escuela Nacional de Antropología e Historia de la Ciudad de México, por uno de los autores (Viñas, 1989) fue publicado el primer estudio sobre el conjunto rupestre de Abrigo Tlaloc (Nicolau, Viñas y Esquivel, 1991). En el citado trabajo se indicaba que el sitio constituia un espacio ri- tual "santuario u oratorio" dedicado a Tlaloc, dios de la lluvia, la tierra y la agricultura. Además, en el artículo, se incluian consideraciones en torno a los materiales arqueológicos observados en superficie, sobre el suelo del abrigo, así como en sus alrededores, destacando la existencia de una cueva sepulcral conocida como Cueva del Gallo. Aquel trabajo inicial puso de relieve la existencia de un extraordinario conjunto ritual desarrollado entre los periodos Formativo y Posclásico.

(*) Roberto Martinez: Profesor/investigador del Instituto de Investigaciones Históricas de la UNAM, (México). Av. del Imán nº60 ed. 30-501; e-mailmopomopa@yahoo.es,

LUIS MoRET: Profesor-investigador INAH, Universidad Autónoma Chapingo (México).

RAMÓN VIÑAS: Investigador del IPHES (Tarragona, España), Calle Vimbodi nº 6, 43400 Montblanc (Tarragona, España), o Calle 21, n76-601, Col San Pedro de los Pinos, (México DF), e-mail rupestrologia@yahoo.es 
En el transcurso de nuestras primeras visitas al lugar ${ }^{1}$ (1989-1990) detectamos varias excavaciones furtivas (pozos de saqueo), tanto en las estructuras prehispánicas, ubicadas en las proximidades, como en el interior de la Cueva del Gallo (buscadores de tesoros)2. En el interior de la citada cueva, y en el borde de uno de los pozos de saqueo, observamos numerosos restos humanos, vegetales, velas y un textil prehispánico que, más tarde, motivó la realización de un primer salvamento por parte del Instituto Nacional de Antropología e Historia (Inah:1992). El interés arqueológico propició la puesta en marcha del Proyecto Arqueobotánico Ticumán (PAT: 1994-2000), organizado por Ana María Pelz, Luis Morett, Fernando Sánchez y José Luis Alvarado. Este proyecto no sólo procedió a la exploración y excavación arqueológica de la Cueva del Gallo sino que también intervino en el abrigo con pinturas rupestres y en otra caverna cercana, conocida como la Chagüera que, al igual que el resto de cavidades, fue utilizada desde el Formativo.

Las evidencias arqueológicas vinieron a demostrar el tránsito de los espacios rituales subterráneos (desde el Formativo, hace unos 3.200 BP) a los abiertos de los centros ceremoniales de la región (propios del Posclásico). Los últimos trabajos, algunos de ellos publicados en INORA (Martínez, Morett y Viñas, 2007), dieron a conocer el área del abrigo Tlaloc como un espacio ritual donde se llevaron a cabo intercambios entre el mundo de los seres humanos y el de las deidades de la tierra y la lluvia. En él, las sociedades prehispánicas presentaron ofrendas y sacrificios a las divinidades telúricas a cambio de los favores y recursos otorgados, indispensables para su subsistencia ${ }^{3}$.

\section{EL ABRIGO Y SU CONJUNTO RUPESTRE}

El Abrigo Tlaloc se ubica en el Arroyo o Barranca del Gallo, en la región de los Valles Orientales y al Sureste de la Ciudad de Cuernavaca, en el estado de Morelos (a unos 90 $\mathrm{Km}$ al sur de la ciudad de México). La cavidad está orientada al SO y sus coordenadas son: 9908'17" Este y 18०47'47" Norte (Carta topográfica Cuernavaca E14A59, edición de 1973) (Foto 1 y 2).

El abrigo presenta tres áreas:

1. Abrigo, dividido por bloques de antiguos derrumbes.

2. Galería interna, ubicada en la zona NO.

3. Galería inferior, a modo de sótano (adosada a la pared del abrigo, debajo del panel de pinturas centrales).

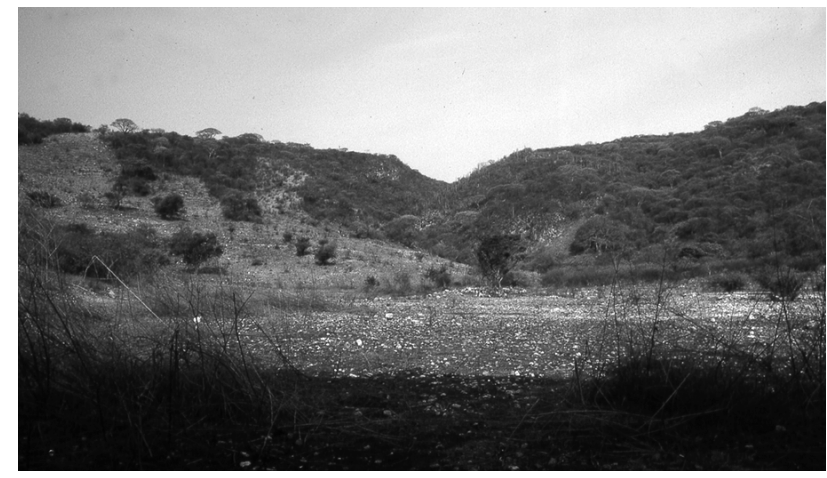

A Fото 1. Barranca del Gallo donde se ubica el conjunto rupestre del Abrigo Tlaloc. (Foto R.Viñas).

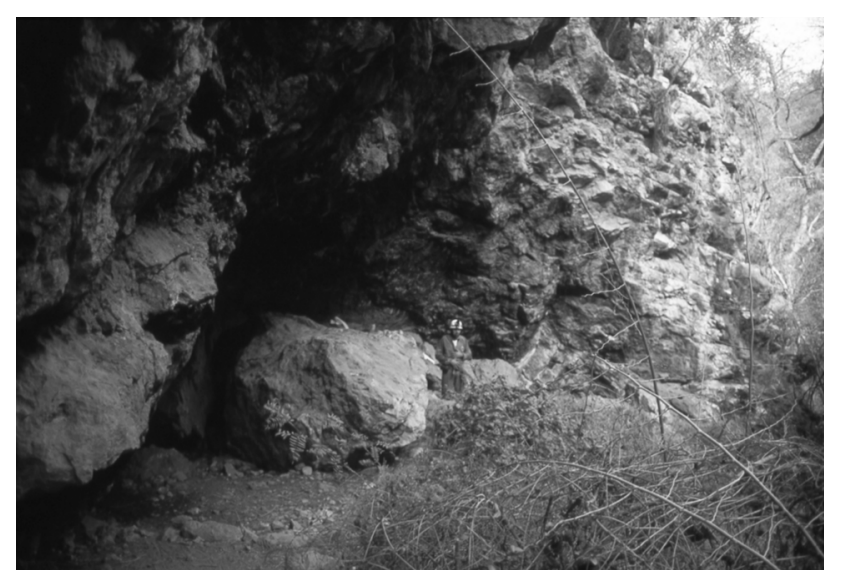

A Fото 2. Vista del Abrigo Tlaloc (Ticumán, Morelos). (Foto R.Viñas).

Sus dimensiones son: $25 \mathrm{~m}$ de largo, $10 \mathrm{~m}$ de profundidad y unos $12 \mathrm{~m}$ de altura máxima. Contiene una galería interna de $2 \mathrm{~m}$ de ancho la cual se prolonga unos $11 \mathrm{~m}$ hacia el interior, $\mathrm{y}$ otra galería inferior o sótano, de unos $2 \mathrm{~m}$ de ancho, que recorre unos $12 \mathrm{~m}$ aproximadamente por debajo del suelo actual. En total, el abrigo cubre una superficie de $90 \mathrm{~m}^{2}$ siendo el área más amplia la sección 1 (Corte $A-A^{\prime}$ ) área con pinturas, a través de la cual se accede a las dos galerías (fig. 1).

\section{a) Las pinturas}

Las imágenes fueron pintadas en tamaños pequeños y medianos (entre 2 y $50 \mathrm{~cm}$ media aprox.), de forma monocroma y en colores blanco o negro, principalmente sobre la pared y en ocasiones en el techo del abrigo (entrada de la galería interna). El discurso pictográfico se reparte en tres áreas (paneles: A-B-C) y constituye 13 asociaciones de figu-

(1). Queremos agradecer a las autoridades del INAH el permiso para llevar a cabo las prácticas del curso de arte rupestre impartido en la ENAH y a los responsables del municipio de Ticumán por las ayudas recibidas y el interés que mostraron para la realización de nuestras exploraciones, asimismo a Albert Rubio en la preparación de los gráficos.

${ }^{(2)}$. Durante una de las primeras visitas a la Cueva del Gallo, la Concejal de Cultura de la población de Ticumán, que nos acompañó hasta el sitio, nos informó que en la localidad se habla de un cofre con monedas de oro escondido en la Cueva. La leyenda ha propiciado, por parte de algunas personas locales, la búsqueda del supuesto tesoro, destruyendo gran parte del patrimonio arqueológico de este conjunto.

(3). Gran parte de la información, expuesta en este trabajo, procede de un artículo de los autores (INORA 2007), publicado en francés e inglés. 


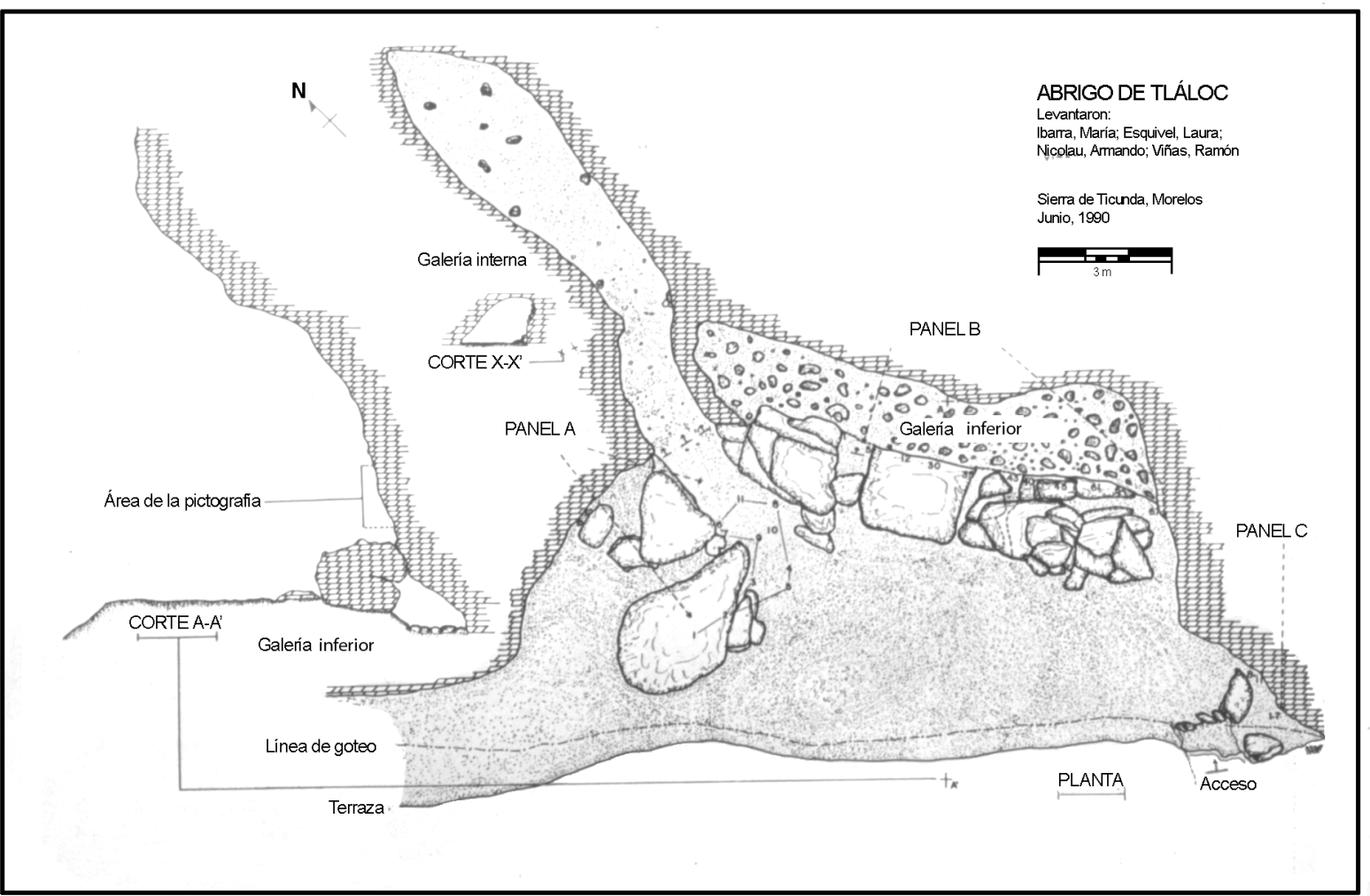

A Figura 1. Planta y sección del Abrigo Tlaloc con la situación de los paneles con pinturas rupestres.

ras de rasgos esquemáticos, que se combinan con manos en negativo, en color negro (foto 4). Prácticamente todos los motivos corresponden a un mismo orden temático, los cuales remiten al observador a un referente iconográfico de claro contenido simbólico.

A juzgar por la variedad y repetición de los temas, se puede alegar que el motivo principal es el rostro de Tlaloc, deidad de la tierra, la lluvia y la vegetación (foto 3$)^{4}$. Su presencia en el abrigo es por lo demás elocuente ya que, como es sabido en el pensamiento indígena prehispánico, el Tlalocan (reino de Tlaloc y también una de las moradas de los muertos) se encontraba en la tierra y se accedía a través de las cuevas.

En cuanto a las unidades compositivas, estas se distribuyen del siguiente modo (figs. 2, 3 y 4):

Panel A (extremo izquierdo del abrigo y techo de entrada de la galería interna).

Integra un motivo radiado enmarcado por una rueda dividida en 18 segmentos, además de puntos formando un círculo, esteliformes, lunas, cuadrúpedos, un par de manos en negativo y una cara del dios Tlaloc (fig. 2).
Panel $B$ (centro del abrigo). Comprende diversas imágenes zoomorfas acompañadas de manos en negativo, elementos esteliformes, figuras lunares, trazos paralelos, una posible tortuga, un rectángulo seccionado (posibles templos), y caras del dios Tlaloc (una de ellas, la principal, complementada con rasgos antropomorfos) (fig. 3).

Panel C (extremo derecho del abrigo). Presenta un triángulo seccionado, un par de caras del dios Tlaloc, manos en negativo y un pequeño elemento antropomorfo de trazo caligráfico (grafito), al parecer de influencia hispana (fig. 4).

Mientras que las manifestaciones rupestres se enmarcan entre los periodos Clásico y Posclásico, las prácticas rituales realizadas en el abrigo y cuevas adyacentes (reconocidas por los materiales arqueológicos) provienen de un horizonte anterior, en el Formativo (en términos generales, este periodo se establece entre el 2000 a. C., a 200 d. C.), $y$, al parecer, antecede al culto del dios Tlaloc ${ }^{5}$.

${ }^{4}$ ). Para los que no están acostumbrados a la iconografía prehispánica de mesoamérica, el rostro del dios Tlaloc se identifica por unas "anteojeras y una bigotera con dientes". Sin ánimos de comparar, y salvando todas las distancias cronoculturales, su concepción simbólica de "ojos y boca" recuerda a la de los ídolos oculados del Bronce europeo.

(5). En la arqueología mesoamericana, el periodo prehispánico se encuentra dividido en cuatro horizontes principales: Formativo, determinado por el inicio de la vida aldeana y la gestación de elementos culturales que caracterizan a esta región; Clásico, momento de mayor apogeo de la cultura mesoamericana y, más particularmente, el máximo esplendor de las sociedades teotihuacana y mayas; Posclásico, horizonte en el que se imponen grandes imperios - primero el tolteca y luego el mexica- los cuales imputan un sistema tributario que comprende buena parte del área mesoamericana. 


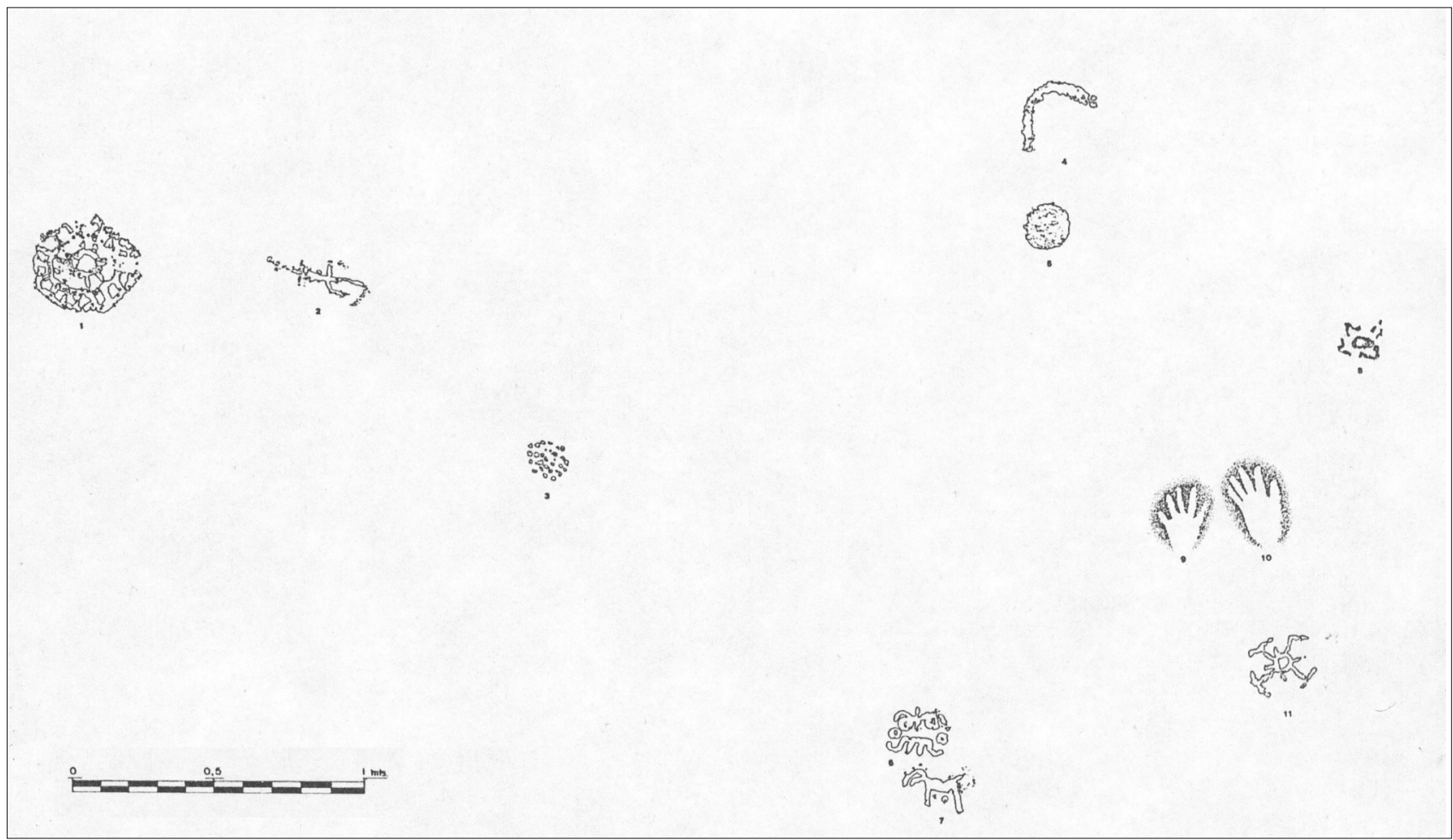

- Figura 2. Panel A. Situado en el extremo izquierdo del abrigo y ocupando el techo de la entrada de la galería interna (Según Viñas, Nicolau y Esquivel).

b) Análisis y referencias etnohistóricas

Entre las imágenes más significativas del mural sobresale al rostro del dios Tlaloc, representado en todos los paneles con cuatro variantes (fig. 5):

1. Rostro-Tlaloc formado por anteojera, bigotera, colmillos y nariz (fig. 5, núm. 1, 2, 4 y 6 )

2. Rostro-Tlaloc anteojera, bigotera y colmillos (fig. 5 , núm. 3).

3. Rostro-Tlaloc con anteojera, bigotera y nariz (fig. 5, núm. 5).

4. Rostro-Tlaloc antropomorfo con anteojera, bigotera, colmillos y nariz, dotado además de cuerpo y tocado (picos o plumas, similar al de algunos códices, como el Borgia: 1993, pl. 16, 19, 20, 25). (fig. 5, núm. 7).

Los pormenores con que fue plasmado el Tlaloc antropomorfo, del área central (panel B), parece indicar la presencia de la deidad misma (foto 3 y fig. 5 , núm. 7 ). Otro de los rostros de este dios (panel $C$ ) se halla asociado a un signo de morfología triangular o vulvar, lo cual podría señalar algún aspecto femenino de la propia deidad; tal vez Chalchiuhtlicue, la consorte de Tlaloc y deidad de las aguas terrestres. En cuanto al resto de representaciones del dios Tlaloc, estas podrían estar emparentadas con los Tlaloques, Tepitocton o Ehecatotontin; deidades menores de la tierra, la lluvia y el viento.
Los colores empleados en la realización de las pinturas son el blanco y el negro; coloraciones típicas de Tlaloc. Una asociación cromática que se ve reforzada por el hecho de que las ofrendas características de esta divinidad son tiras de papel (blanco) manchadas de hule (negro) (ver Códice Borgia: 1993, Fol. 12, 72; Códice Borbónico: 1988, Fol. 18, 20, 25, 26) (Dupey García, 2005, comunicación personal).

Respecto al resto de figuras, señalemos un soliforme, encerrado en el centro de una rueda dividida en 18 segmentos (asociada al calendario solar de 18 meses de 20 dias); muestra una estructura semejante a la de otros monumentos arqueológicos (foto 6). Es interesante precisar que la figura más próxima, a esta rueda calendárica, es precisamente un reptil, similar a un lagarto. De acuerdo con Sahagún (1956: 317) Ce Cipactli ("1-Lagarto") era el primer signo del calendario adivinatorio azteca. Algunas crónicas (Leyenda de los Soles, 1945, 121; Mendieta, 1993, 97; Histoyre du Méchique, 1905, 97), indican que el lugar donde fue creado el tiempo organizado "es decir, el calendario" es Tamoanchan, un sitio paradisíaco parecido al Tlalocan, que según Mendieta y la Histoyre du Méchique debe situarse en una cueva cercana a Cuernavaca, o sea, en la misma región del Abrigo Tlaloc.

En cuanto a los cuadrúpedos, pintados en negro y blanco, algunos parecen cánidos (foto 8), felinos y reptiles (lagarto y una posible tortuga). Sabemos que en el pensamiento de algunos pueblos nahuas contemporáneos de los estados de Guerrero, Puebla y Veracruz, los animales (tanto los ordinarios 


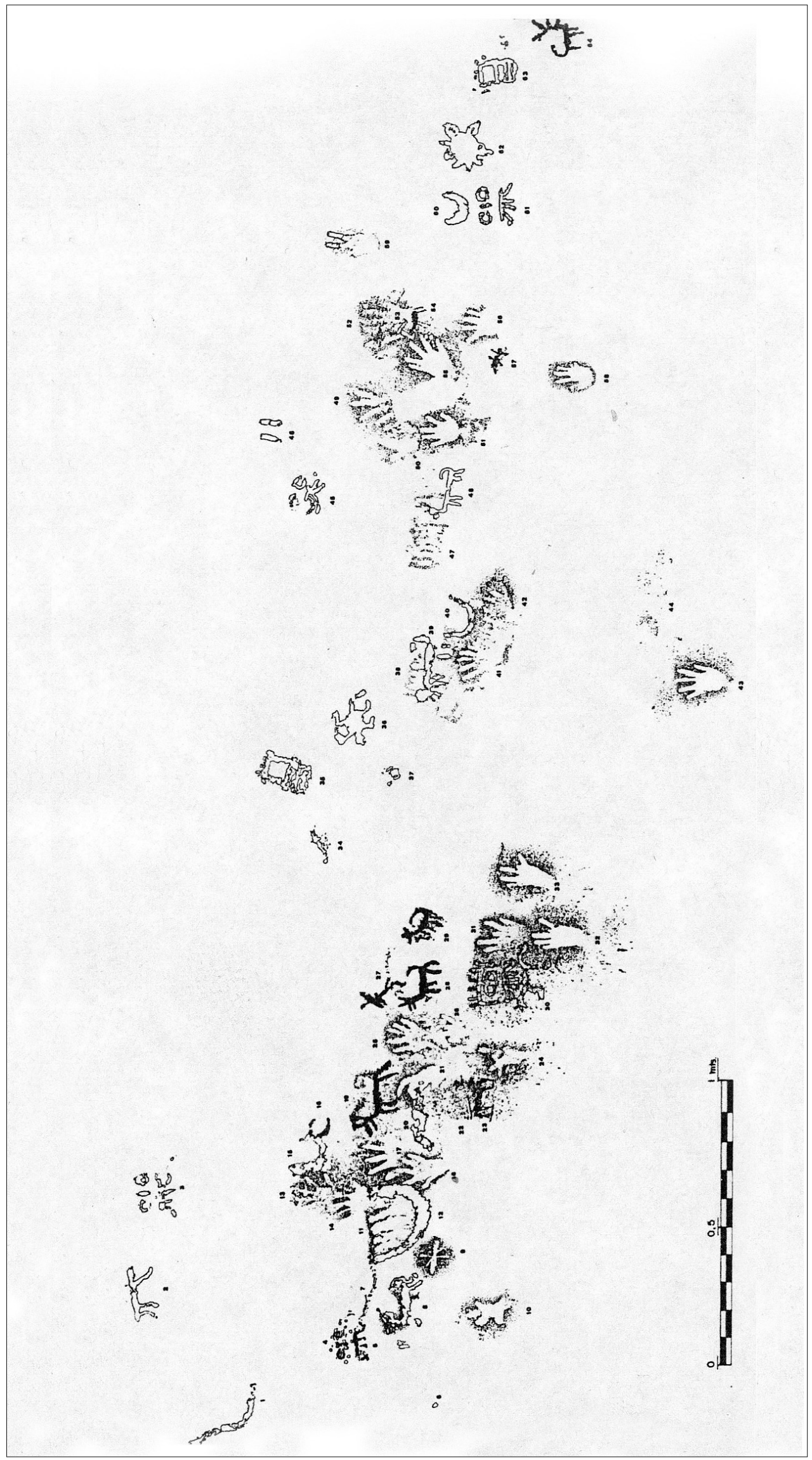

- Figura 3. Panel B. Ubicado en el centro del abrigo, presenta la mayor acumulación de figuras, entre ellas imágenes de zoomorfos, soles, lunas, manos en negativo y diversos rostros del dios Tlaloc (Según Viñas, Nicolau y Esquivel). 
como aquellos con los que los seres humanos comparten su alma -llamados naguales-) tienen un hábitat subterráneo al interior de las montañas y bajo el cuidado de ciertas deidades telúricas, a veces llamadas Talokanca (Beaucage, 199091; Sánchez y Díaz, 1978: 221; Neff, 2001: 362; Reyes García y Dieter, 1990: 80-88; Lazos y Paré, 2000: 68).

Otro componente importante del mural lo constituyen las figuras de astros (fotos 5 y 6 ). Aunque la mayoría se hallan ubicados en puntos elevados de la pared, en ocasiones se les localiza en el mismo nivel que el resto de motivos. Es muy posible que tales elementos conformen la imagen de un firmamento nocturno pensado como un cielo infraterrestre o subterráneo, pues en las creencias prehispánicas, los astros tenían que pasar por el mundo de los muertos antes de saltar a la bóveda celeste, y de acuerdo con Graulich (1981: 323) "el periodo que precede el amanecer, es el Mictlan (...) la noche estrellada sería en realidad el inframundo que invade el cielo cuando el sol pasa bajo tierra".

Algunas de las representaciones selénicas señalan distintas fases (plenilunio, menguante, creciente) y tal vez indiquen alguna forma de variación temporal (ciclo, o alternancia de momentos húmedos y secos). En la mayor parte de tales imágenes, la luna aparece como abierta hacia arriba, una forma estereotipada con la que figura en los códices y las manifestaciones rupestres de la región (foto 5 ).

Cabe señalar que la luna se encuentra más estrechamente vinculada al Tlalocan que ningún otro astro. El primer cielo fue conocido como in Tlalocanpanmeztli "el cielo del Tlalocan en la Luna" (Códice Vaticano A, 1966: 8-10, pl. 11-12).

Entre los grupos de puntos, aparece una unidad compacta que tiende a conformar un óvalo (foto 7). Aunque no descartamos la posibilidad de que se trate de una representación simbólica de una nube portadora de lluvia y gotas de agua, la imagen también es similar a la de un hormiguero que aparece en el Códice Azcatitlan (1995, Fol. 2). En la mitología náhuatl, es precisamente la hormiga quien penetra en la montaña de los mantenimientos para obtener el maíz con que alimentar a los seres humanos; posteriormente, este cereal fue acaparado por las divinidades de la tierra (Leyenda de los Soles, 1945: 121).

En cuanto a los rectángulos seccionados, cabe mencionar que su estructura formal es parecida a la de los templos vistos de frente, los cuales aparecen representados en grabados y pinturas rupestres, sin embargo este morfotipo requiere de más estudios.

Por último, destaquemos como elemento esencial las improntas de manos en negativo, de color negro, presentes en todos los paneles del abrigo (foto 4). Estas tienden a sobreponerse y acumularse en distintas partes del abrigo, en particular alrededor del Tlaloc antropomorfo (foto 3). Si bien anotamos, en trabajos precedentes, que éstas podrian ser un elemento simbólico testimonial: "participación en algún ritual, o imploración colectiva, como petición de lluvia", hay

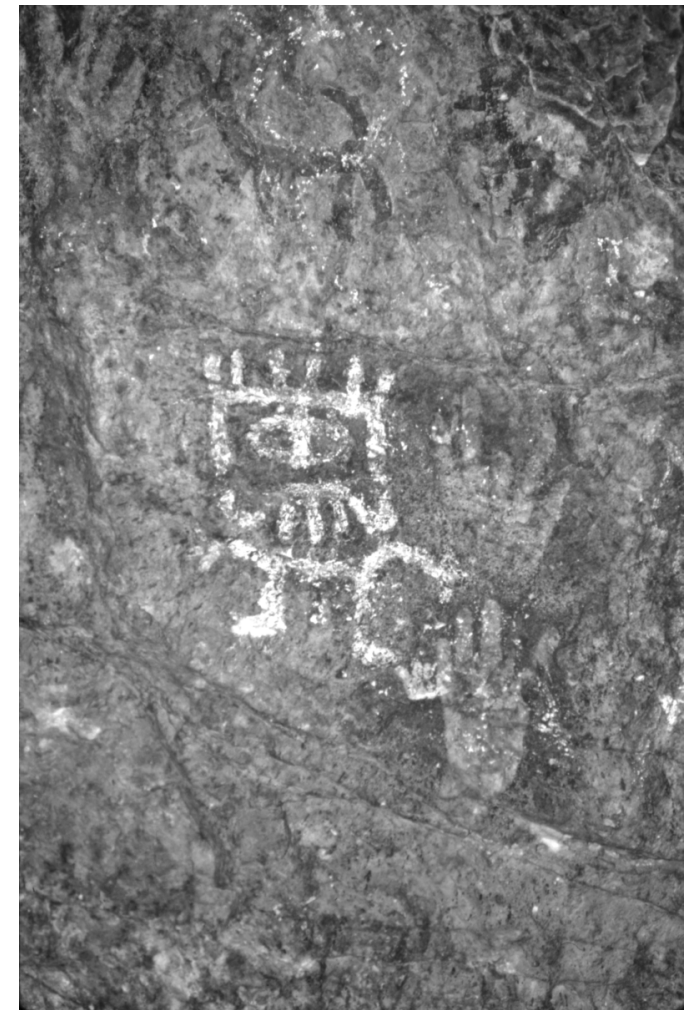

A Fото 3. Representación principal del dios Tlaloc (panel B). Su situación, en el centro del conjunto, y sus rasgos antropomorfos lo distinguen del resto. A su lado se distinguen varias manos en negativo de color negro (Foto R.Viñas).

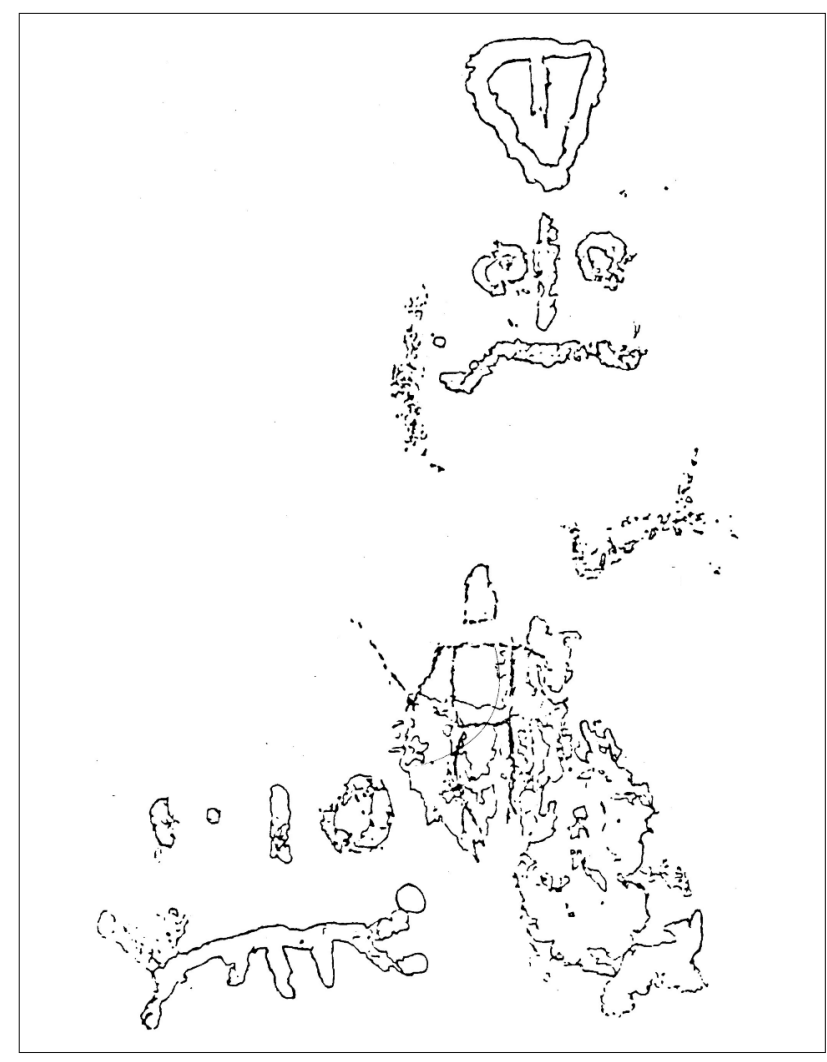

- Figura 4. Panel C. Se localiza en el extremo derecho del abrigo (Según Viñas, Nicolau y Esquivel). 


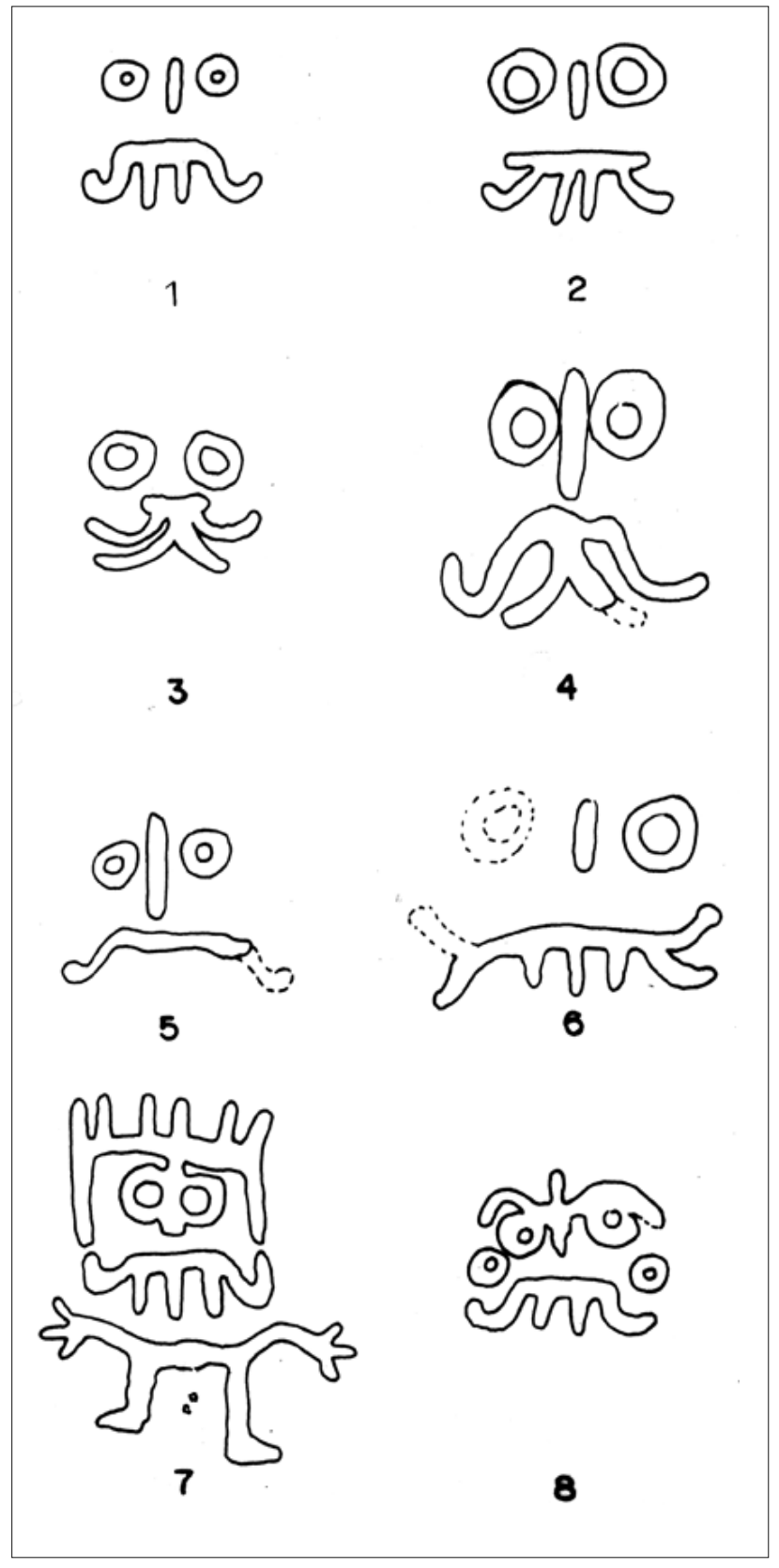

A Figura 5. Distintas variantes del rostro del dios Tlaloc, representado en los paneles del Abrigo Tlaloc.

que añadir que en diversos códices aparecen "manos" sobre las bocas de diferentes deidades, y constituyen un atributo característico de los Macuil tonaleque; los guerreros muertos en batalla que acompañaban al sol en su viaje del inframundo al cenit, para después transformarse en colibries (ver Códice Florentino, 1950 III, 47; Códice Borgia, 1993, Fol. 7, $10,15,47)$. En estos documentos [de tradición prehispánica pero, al parecer, realizados en época del contacto hispano] encontramos la representación de "manos", empleadas como pendientes o collares en las imágenes de los dios es Mic- tlantecuhtli y Tzitzimitl -asociados a la muerte- y asimismo en la estatua monumental de Coatlicue, expuesta en el Museo de Antropología de la Ciudad de México (ver Códice Borgia, 1993, Fol. 13, 16, 17, 56; Códice Tudela, 1980). También hallamos "manos" entre las pinturas de árboles floridos de Techinantitla (Teotihuacan), además se observan "manos" amputadas acompañando el entierro de un neonato en Teotihuacan (Escalante Gonzálbo, 2005: 20-27), y asimismo se localizaron, fragmentos de ellas, entre las ofrendas agrícolas de las cuevas aledañas al Abrigo Tlaloc. En opinión de E. Gonzálbo las "manos", en el pensamiento prehispánico del Centro de México, se encuentran asociadas a la muerte y el paso por el mundo de los muertos (Ibídem, 26).

\section{c) Interpretación del conjunto rupestre}

Las manifestaciones rupestres del Abrigo Tlaloc nos remiten a los siguientes significados:

1. El abrigo [con dos galerías] como entrada al inframundo y en particular al Tlalocan [reino de Tlaloc y destino de ciertas victimas]. La imagen misma del rostro de Tlaloc sugiere su dominio sobre la tierra, la lluvia, la fertilidad, los alimentos y todas las formas de riqueza existentes. Dentro de este contexto simbólico, destaca la presencia de un Tlaloc asociado a un atributo, al parecer, femenino (Chalchiuhtlicue), y posibles templos asociados al culto de la tierra y la lluvia.

2. El conjunto de cavidades subterráneas como acceso al Mictlan, la morada de los muertos, representada por los hallazgos de restos humanos en las cercanas cuevas del Gallo y la Chagüera, así como las figuras de posibles cánidos y manos en negativo del abrigo. Un complejo ceremonial de carácter funerario y ofrendario, desde el periodo Formativo hasta el Posclásico. El conjunto pictórico presidido por la imagen antropomorfa de Tlaloc se enmarcaría en el periodo Clásico.

3. El abrigo-Tlalocan-Tamoanchan como lugar de origen del cómputo calendárico y la organización del tiempo. Si los distintos motivos selénicos representan los cambios en las fases lunares, posiblemente se estaria haciendo referencia a los ciclos naturales que ritman los periodos de reproducción y muerte.

4. El abrigo-Tlalocan como lugar de la noche, residencia de astros nocturnos -incluyendo al sol en su paso por el inframundo- situada al mismo tiempo en la tierra y el cielo de la luna.

5. El abrigo-Tlalocan como morada de animales ${ }^{6}$ y posiblemente animales-naguales ligados al desarrollo de los individuos al interior de la sociedad.

(6) Tal vez, y en el caso de los cánidos, se trate de recursos explotables o quizás de acompañantes de los muertos. También hay que tener en cuenta que los muertos se manifiestan sobre la tierra como animales, lo cual hace más compleja su interpretación. 


\section{CONTEXTO ARQUEOLÓGICO}

La simple presencia de la temática rupestre y las cuevas con entierros y ofrendas agrícolas, habría sido suficiente para comprender que todo este espacio geográfico había sido seleccionado con propósitos rituales, incluso mucho antes de instituirse el culto a la deidad abordada en este texto.

Entre 1994 y 1998, el proyecto Arqueobotánico Ticumán, excavó el abrigo Tlaloc y las cuevas del Gallo y la Chagüera. Los trabajos arqueológicos en las cuevas demostraron que el $80 \%$ de los hallazgos pertenecían al periodo Formativo, el 3\% al Clásico y el $17 \%$ al Posclásico. En los complejos subterráneos destacó la presencia de entierros primarios y secundarios. Los primarios aparecieron asociados a ofrendas; mientras que los secundarios, generalmente múltiples, se hallaron despojados de material acompañante (Morett et al., 1999 a y b).

Los exámenes realizados sobre el contenido de las ofrendas permitieron establecer que algunas fueron integradas a deposiciones anteriores o contenían restos de antiguos dones. Tal disposición sugiere que la actividad ofrendaria habría sido en algunos casos una acción de renovación ritual, donde los nuevos materiales se sumaron a los ya existentes (Morett et al., 1999b vol. III, 7).

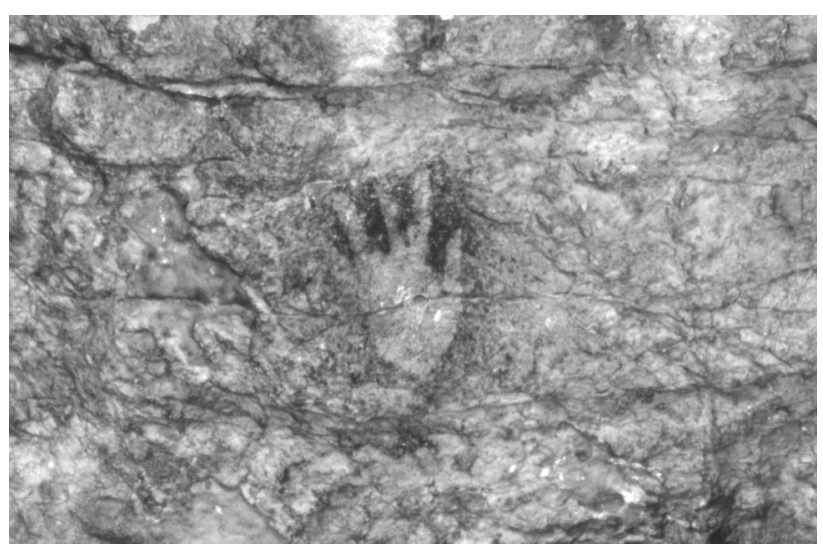

A Fото 4. Mano en negativo del Abrigo Tlaloc. Estas representaciones aparecen aisladas o en pares, y en casos concretos esconden o carecen de algún dedo (Foto R.Viñas).

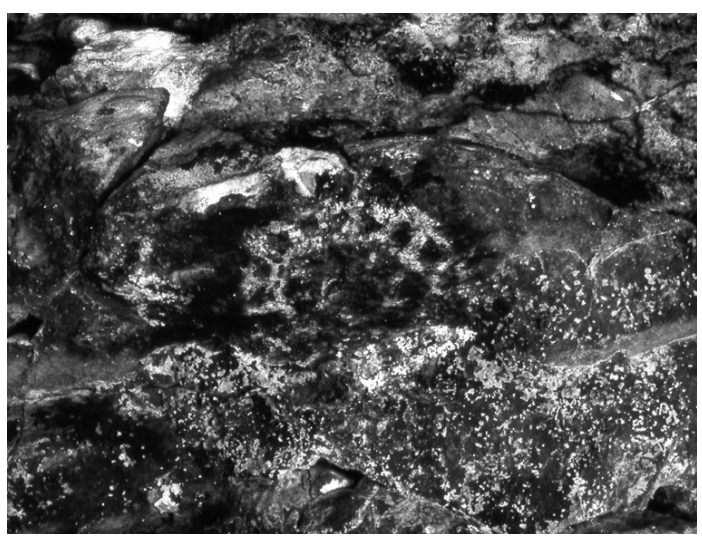

A Fото 6. Soliforme (centro) y rueda calendárica (Foto R.Viñas)

\section{EXCAVACIONES EN EL ABRIGO TLALOC}

En 1998 se excavó el depósito del abrigo Tlaloc. Los trabajos comprobaron que la superficie del abrigo era una aglomeración de piedra y tierra (producto de desplomes naturales), combinados con muros de contención, rellenos y nivelaciones intencionales de época prehispánica. Al igual que en las cuevas, el abrigo había sido utilizado desde el Formativo Medio y Tardío hasta el Clásico, seguido de un intervalo sin materiales, hasta el final del Posclásico. Posteriormente, otro gran hiato continúa hasta el siglo XIX, momento en que se registran materiales de visitas locales y el uso como refugio durante la Revolución Mexicana, para finalizar con un nuevo corte ritual en torno a los pasados años noventas.

La limpieza del talud, que desciende del abrigo, liberó una escalera de piedra (rocas escalonadas), que permitían el acceso a la zona central. En ésta parte se recuperaron algunos fragmentos de cerámica, en su mayoría del Formativo, y unos pocos del Clásico y Posclásico. En la excavación de la plataforma del abrigo, y hasta 1 metro de profundidad, aparecieron otros fragmentos de vasijas prehispánicas, mezclados con el relleno, generado para nivelar el suelo. Además, se hallaron 17 concentraciones de material orgánico (al pare-

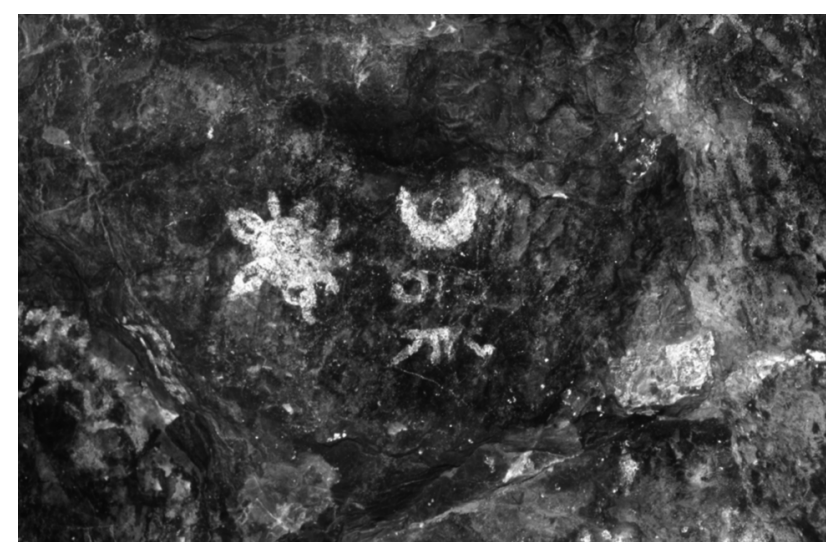

- Fото 5. Representación del rostro de Tlaloc asociado a elementos estelares (Foto R.Viñas).

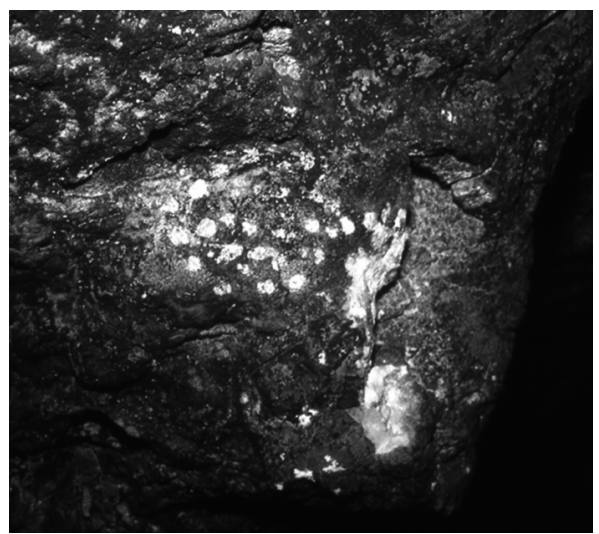

A Fото 7. Agrupamiento de puntos, interpretado como hormiguero o nube con gotas de agua (Foto R.Viñas). 


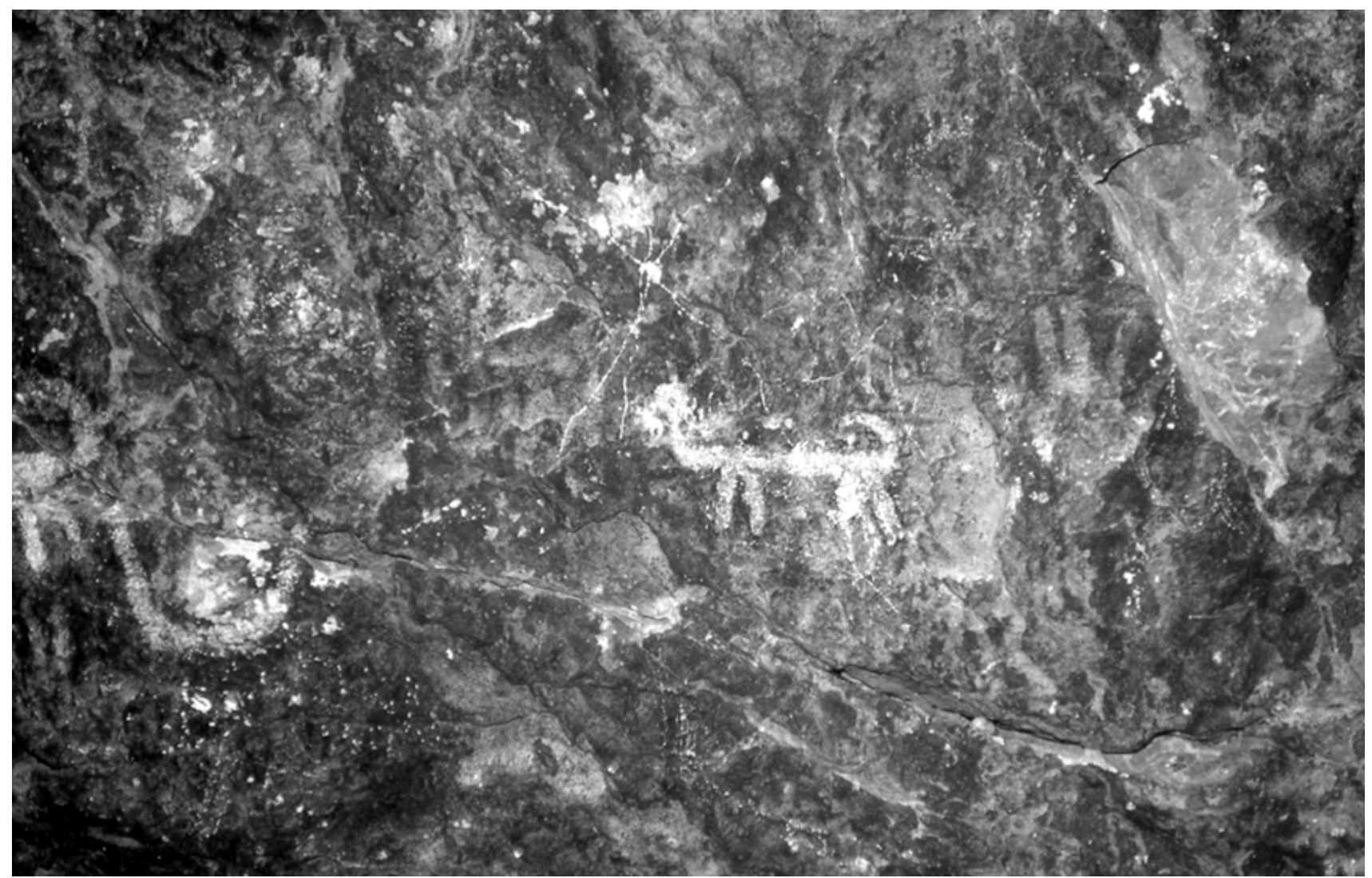

- Fото 8. Cuadrúpedo (posible cánido) junto a manos en negativo (Foto R. Viñas).

cer deposiciones secundarias de ofrendas), procedentes de las remociones del depósito. La ofrenda número 1 estaba formada por un entierro secundario, el cual integraba fragmentos de tibia y cráneo humanos, acompañados de un cajete incompleto del Formativo Tardío. La ofrenda número 2 (situada en la entrada de la galería interna) se hallaba cubierta de piedras y guano de murciélago; esta ofrenda reciente contenía restos de papel, carbón, cerámica, ramas, un fragmento de periódico, y una gran concentración de material botánico: restos de olotes, hojas y tallos de maíz, entremezclados con semillas de ayoyote y mezquite, fragmentos de vainas, todo ello entremezclado con velitas de madera, vidrio, cerámica, heces fecales y restos de correas. Una tercera ofrenda similar, quizás parte de la anterior, se localizó a su derecha, esta contenía semillas de ayoyote, hojas y tallos, fragmentos de olotes, hojas de maíz, copros, restos óseos de ave y mamífero, corteza de madera, semillas de guaje, chupandilla, capire, y también un billete del Gobierno Provisional, revalidado en 1914.

Debajo del panel central de las pinturas y a unos $20 \mathrm{~cm}$ de la superficie se localizaron las ofrendas 4 y 5 , las más significativas del abrigo, ambas se encontraban muy próximas y pudieron formar parte de un mismo depósito. Integraba una base de bagazos de agave sobre la cual se encontraron abundantes olotes. Tanto la disposición como la composición de los mismos era similar a las encontradas en las cuevas ad- yacentes. Entre los materiales fue recuperada una coa de cobre con parte de mango o asa de madera, posiblemente del Posclásico (lbídem, 169). Además del agave y el maíz, la ofrenda contenía un fragmento de lasca y navajilla de obsidiana, restos de cerámica, un diente humano, tela, un hueso largo de animal cortado, restos de ave y conejo, fragmentos de madera y carbón, cordeles, hilos, ovillos, pencas desfibradas, trenzas y anudados de palma, frutos de tecomate, semillas de mezquite, ayoyote, capire, ciruela, chile, chupandilla y gramíneas varias, restos de pericarpio y pedúnculos de calabaza, y fragmentos de guajes.

Al examinar la galería inferior o sótano (que no fue excavado), se detectaron en superficie restos óseos de distintas especies de animales, al parecer ofrendas tardías y recientes. Asimismo en la galería interna, se encontraron restos de un conjunto ofrendario también reciente, que se haIlaba compuesto por tela quemada, el esqueleto completo de un gallináceo -cuyas patas estaban atadas-, plumas negras, 20 cigarros completos sin filtro, restos de flores y tallos de bugambilias y gladiolas, 61 monedas de distintas denominaciones (100, 500 y 10 pesos), con cuños entre 1987 y 1990, además de fragmentos de vasos de veladora, cascarones de huevo, listones blancos, restos de una botella y cera (Morett et al., 1999 a. vol. I, 33). Este tipo de ofrenda parece ser la continuación ancestral de los ritos agrícolas prehispánicos, por parte de los pueblos aledaños. 


\section{EXCAVACIONES EN LAS CUEVAS DEL GALLO Y LA CHAGÜERA}

En estas cuevas se excavaron más de una docena de ofrendas. Como elementos comunes aparecieron "artefactos manufacturados con fibras de maguey y palma, además de restos óseos humanos y animales (perros y aves), todo ello depositado generalmente sobre una cama de pastos o gramíneas y cubierto por una capa de lodo y rocas, ya sea envueltos o no por un textil, y depositados en alguna estrecha y escondida grieta del interior de las cuevas" (Sánchez et al., 1998) (foto 9). Entre las ofrendas descubiertas, el maíz fue el elemento más cuantioso, este se halló como un producto maduro a través de restos de mazorcas, olotes, granos, hojas envolventes, tallos y raíces. La abundancia de este producto alude, sin lugar a dudas, a la función protagónica que tenía esta especie vegetal, y fundamentalmente en lo simbólico dentro del mundo mágico-religioso.

En las ofrendas hay que destacar la presencia de restos óseos humanos (manos, pies, costillas y vértebras); lo que sugiere la práctica de sacrificios y su asociación al desmembramiento. Como prueba, de la existencia de prácticas autosacrifícales, se encontró "una pequeña caja manufacturada con palma, que contenía espinas de maguey y navajillas" (de obsidiana) (Morett et al., 1999b vol. III, 10).

Los restos de plantas agrícolas, halladas en las ofrendas, permitieron conocer tanto las diversas especies como la época del año, estos actos fueron practicados a fines de estío, entre abril y mayo, justo antes de iniciarse la temporada de Iluvias, y, con ella, la temporada agrícola. La abundante cantidad de olotes previamente desgranados, los granos de maíz y las evidencias de insectos (palomillas), que en ellos se incubaron indica que radicaba en un producto muy maduro. (lbídem, 10).

\section{CONCLUSIÓN}

Las referencias etnohistóricas y la analogía etnográfica, aplicada al estudio del mural del Abrigo Tlaloc, nos ha permitido reconocer e interpretar las figuras rupestres y establecer, con las evidencias arqueológicas, los patrones del comportamiento ritual (antiguo y reciente) asociado al culto en las cuevas.

El Abrigo Tlaloc constituyó una especie de reproducción microcósmica del Tlalocan en la que se encontrarían plasmados los diversos aspectos del dominio del dios Tlaloc. En este sentido, el abrigo, actuó como una especie de Encanto; un espacio que, en el pensamiento indígena contemporáneo, funge como pequeña manifestación o puerta al inframundo. Se trata pues, de sitios en los que ambos mundos, social y sobre-natural, se encuentran y permiten el libre tránsito de sus seres (Goloubinoff, 1994: 576; Duquesnoy, 2001: 371 y Münch, 1994: 173-176). Es precisamente en dichos espacios que los especialistas rituales antiguos y contemporáneos han buscado la manera de entablar contacto directo con las deidades que detentaban los recursos indispensables para la subsistencia del grupo. $Y$ es en dichos espacios que, a través de la invocación de los poderes germinales y convocando a la lluvia, se habría de asegurar la germinación y la provisión de los bienes indispensables para el mantenimiento de las sociedades prehispánicas y actuales.

Las ofrendas fueron depositadas como una súplica y símbolo propiciatorio, los restos del consumo y los restos no consumidos, tales como restos de sacrificios humanos o de animales, acompañados de granos y mazorcas, constituyeron el regalo de alimento destinado a las fuerzas germinales. "La asociación de símbolos esenciales, granos de maíz y segmentos humanos (encontrados en las oquedades de las cuevas adyacentes), no son sino elementos de un mismo código relacionado con las potencias germinales que alimentan a los seres humanos y que deben nutrirse cíclicamente a través de la repetición del ritual y la renovación de la ofrenda" (Morett et al., 1999b., vol. III: 9-10).

- Fото 9. Interior de la Cueva del Gallo. Las exploraciones revelaron la existencia de restos humanos y ofrendas que fueron excavados durante el Proyecto Arqueobotánico Ticumán (PAT: 1994-2000) (Foto R.Viñas).

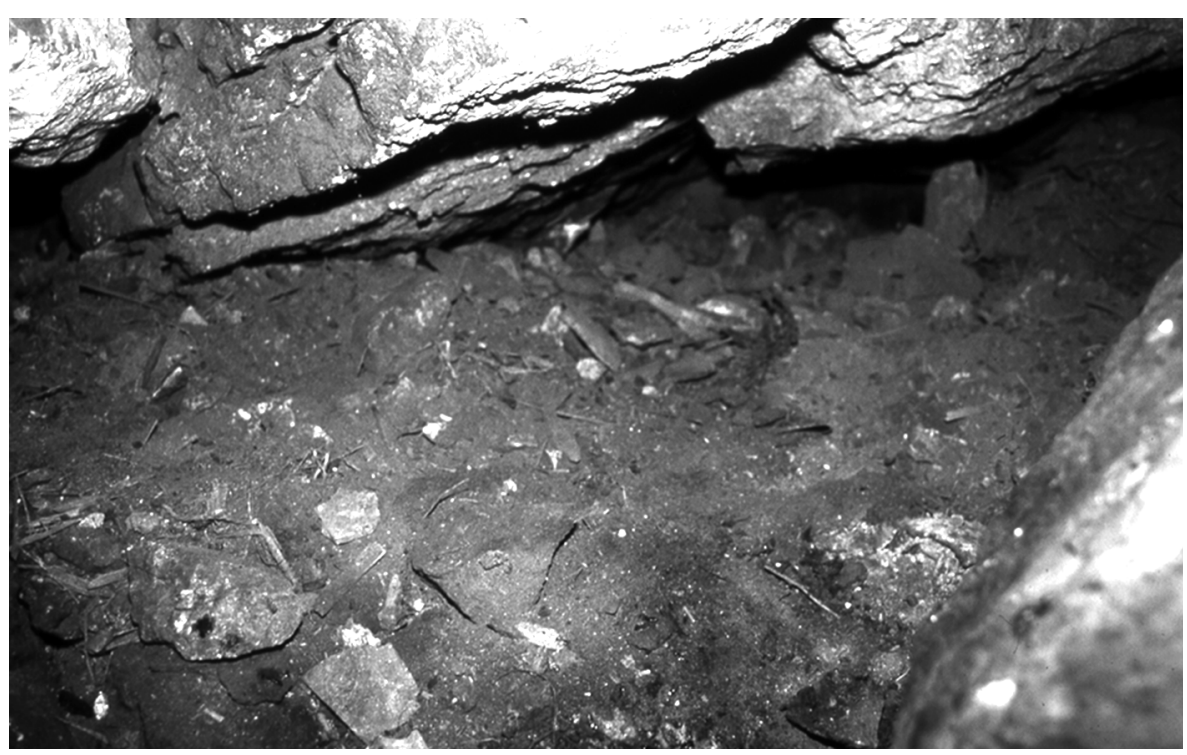




\section{BIBLIOGRAFÍA}

José Luis Alvarado, Jorge Luis Jiménez-Meza, Luis Morett-Alatorre, Ana María Pelz Marín y Fernando Sánchez-Martinez (1996): Proyecto Arqueobotánico Ticumán 94.Cueva de la Chagüera. Primeros avances. In Memoria del Tercer Congreso Interno del Centro INAH Morelos 1994. Instituto Nacional de Antropología e Historia. México, p.p.131-147.

- Códice Azcatitlan. 1995 Michel Graulich, Robert Barlow, Leonardo López Lujan, Dominique Michelet (Comité de investigación). Bibliothèque Nationale de France y Société des Américanistes. Paris.

- Códice Borbónico: Homenaje para el fuego nuevo. 1991 Ferdinand Anders, Maarten Jensen y Luis Reyes (Comité de investigación). Sociedad Estatal 5nto Centenario, España. Akademische Druk-u Verlagsanstalt, Fondo de Cultura Económica. México.

- Códice Borgia: Los templos del cielo y de la oscuridad Oráculos y liturgia. Ferdinand Anders, Maarten Jensen y Luis Reyes (Comité de investigación). Sociedad Estatal 5nto Centenario, España. Akademische Druk-u Verlagsanstalt, Fondo de Cultura Económica. México.

- Códice Chimalpopoca. Anales de Cuauhtitlan y Leyenda de los Soles. 1945 Instituto de Investigaciones Históricas. México.

DUPEY GARCÍA ELODIE (2003): Color y cosmovisión en la cultura náhuatl prehispánica. Tesis para optar por el grado de maestra en estudios mesoamericanos. Facultad de Filosofía y Letras, UNAM. México.

DUQueSNOY, Michel (2001): Le chamanisme contemporain Nahua de San Miguel Tzinacapan, Sierra Norte de Puebla, Mexique. Thèse pour obtenir le grade de Docteur de l'Université de Lille 3. Discipline Ethnologie, CNRS, Lille.

Escalante Gonzalbo, Pablo (2005): Manos y pies en Mesoamérica In Arqueología Mexicana vol. XII, n 71. Ed. Raices- Instituto Nacional de Antropología e Historia. México. 20-27.

FloRentine CodeX (1950-1963): General History of the Things of New Spain. Arthur J. O. Anderson, Charles E. Dibble (trads.). Monographs of the School of American Research. Santa Fé, Nuevo México.

GoloubINOFF, MARINA: Relations sociales et commerce chez les Indiens nahuas $d u$ Balsas. Thèse présentée en vue du grade de docteur de I'université de Paris X. 2 vols. Laboratoire d'ethnologie sociologie comparative. Nanterre.

GRAulich, Michel (1981): The metaphor of the day in ancien mexican myth and ritual. In Current Anthropologie. vol. 22, n 1. The Wenner-Green Fondation for Anthropological Research.

LAZOS, ELENA Y PARÉ, LUISA (2000): Miradas indigenas sobre una naturaleza entristecida. Percepciones del deterioro ambiental entre nahuas del sur de Veracruz. Instituto de Investigaciones Sociales. UNAM, Plaza y Valdés. México.

López Austin, Alfredo (1994): Tamoanchan y Tlalocan. Fondo de Cultura Económica. México.

Martínez, R.; Moret, L. y ViñAS, R. (2007): "Rock Art of the Abrigo Tlaloc. A ritual space for the Rain God and agriculture (Ticumán, Mexico"), INORA, n 47, pp. 20-29. Foix, Francia.

MENDIETA, JERÓNIMO DE (1993): Historia eclesiástica indiana; obra escrita a fines del siglo XVI. Joaquín García Icazbalceta (Ed.). Porrúa. México.

Morett Alatorre, Luis; Sánchez Martinez, Fernando y Alvarado, José Luis.
(1999 a): Proyecto Arqueobotánico Ticumán. IV Temporada de Campo. Informe de Campo, en Proyecto Arqueobotánico Ticumán. IVTemporada 1998. vol.1. Informe Técnico. Mecanuscrito en el Archivo Técnico de Prehispánicos. Instituto Nacional de Antropología e Historia. México. 10-197.

Morett AlatorRe, L.; SÁnchez-Martínez, F. y Albarado, J. L. (1999 b): Ofrendas agrarias del Formativo en Ticumán, Morelos México. In Proyecto Arqueobotánico Ticumán. IV Temporada 1998. Estudios. vol. 3.2-20.

Morett Alatorre, luis; SÁnchez Martinez, Fernando y Alvarado, José luis (2000): Ofrendas agrarias del Formativo en Ticumán, Morelos. In Arqueología, historia y antropología. In memoriam José Luis Lorenzo. B. Jaime Litvak y Lorena Mirambell (coords.), Colección Científica $n^{\circ} 415$. Instituto Nacional de Antropología e Historia. México. 103-115.

Morett Alatorre, LUIS (1999): Las pinturas rupestres del Abrigo de Tlaloc. Aproximación a su significado. In Proyecto Arqueobotánico Ticumán. IV Temporada 1998. vol.3. Estudios. Mecanuscrito en el Archivo Técnico de Prehispánicos. Instituto Nacional de Antropología e Historia. México. 58-85

Morett Alatorre, luis; Sánchez Martinez, Fernando; Alvarado, José luis y Pelz Marín, Ana María (1999): Proyecto Arqueobotánico Tucumán. In Arqueología mexicana n³6, vol.VI. Marzo-Abril 1999. Editorial Raices, México.

MüNCH GuIDo (1994): Etnología del Itzmo veracruzano. Instituto de Investigaciones Antropológicas, UNAM. México.

Neff Francolse (2001): Lucerna y Volcán Negro. In La montaña y el paisaje ritual. Johanna Broda (Ed.). Instituto Nacional de Antropología e Historia, Consejo Nacional para la Cultura y las Artes, México.

Nicolau, ARMANDO; Viñas, RAmón y EsQuivel, LAURA (1991): Representaciones del dios Tlaloc en un conjunto de pinturas rupestres, Morelos. In Antropológicas n 6. Instituto de Investigaciones Antropológicas, UNAM, México. 8-19.

Reyes Garcia, Luis y Dieter Christensen (1990): El Anillo de Tlalocan. Mitos, oraciones, cantos y cuentos de los Nawas actuales de los Estados de Veracruz y Puebla. Centro de Investigaciones y Estudios Superiores en Antropología Social, Fondo de Cultura Económica Fundación Quinto Centenario. Gobierno del Estado de Puebla, México.

Sahagún, Bernardino de (1938/1956): Historia General de las Cosas de la Nueva España. Editorial Pedro Robledo. Mexico.

SÁnchez y Díaz de Rivera, María EugenIA (1978): Temps, espace et changement social. Perspectives à partir de la communauté indigène de San Miguel Tzinacapan. Thèse doctorale. Ecole des Hautes Etudes En Sciences Sociales. Paris.

Sánchez Martínez, Fernando; José luis Alvarado y Luis Morett Alatorre (1998): Las cuevas del Gallo y de la Chagüera. Inventario arqueobotánico e inferencias. In Arqueología n¹9, segunda época. Enero-junio 1998. Revista de la Coordinación Nacional de Arqueología del Instituto Nacional de Antropología e Historia. México. 81-89.

TALleR de tRadición ORAL del CEPEC y BeAuCAge PieRre: Le bestiaire magique: Categorisation du monde animal par les maseuals (Nahuats) de la Sierra Norte de Puebla. In Recherches Amerindiennes au Québec vol. 20, n³-4. Bibliothèque Nationale du Québec. Montréal. 